\title{
Clinicopathologic Features and Prognostic Factors in Alpha-Fetoprotein-Producing Colorectal Cancer: Analysis of 78 Cases
}

\author{
Yang Feng ${ }^{a, b}$ Yaqi Li ${ }^{a, b}$ Weixing Daia ${ }^{a, b}$ Shaobo Mo ${ }^{a, b}$ Qingguo Lia,b \\ Sanjun Caia,b
}

aDepartment of Colorectal Surgery, Fudan University Shanghai Cancer Center, Shanghai, bepartment of Oncology, Shanghai Medical College, Fudan University, Shanghai, China

\section{Key Words}

Alpha-fetoprotein $\cdot$ Colorectal cancer $•$ Propensity score matching $\bullet$ Liver metastasis $\bullet$ HGF/cMet signaling pathway

\begin{abstract}
Background/Aims: Alpha-fetoprotein-producing colorectal cancer (AFPP-CRC) is quite rarely seen. This study aimed to elucidate the clinicopathologic characteristics and prognostic factors of AFPP-CRC. Methods: Among 5,051 colorectal cancer patients receiving surgery in the Fudan University Shanghai Cancer Center from 2006 to 2016, we identified 78 patients with elevated serum level of AFP (>10 $\mu \mathrm{g} / \mathrm{L})$ preoperatively. A propensity score matching (PSM) analysis was performed which matched 75 AFPP-CRC patients to the same number of AFP-negative colorectal cancer (AFPN-CRC) patients. Kaplan-Meier curves were compared using the logrank test and multivariable analysis was performed to evaluate the effect of AFP-positivity while adjusting confounding factors. 27 patients were available for immunohistochemical analysis. We conducted functional experiments to characterize the tumorigenicity of AFP. Results: Patients with AFPP-CRC had a significantly higher incidence of advanced TNM stage and liver metastasis. Overall survival was significantly different between two groups before and after PSM, and AFP-positivity was one of the strongest predictors of overall survival in the multivariable model (HR 4.11, Cl 95\%: 1.43-11.76, $\mathrm{p}=0.009$ ) after PSM. We further investigated prognostic factors affecting prognosis in AFPP-CRC and found that the presence of liver metastasis was the only independent prognostic factor (HR 4.95, CI 95\%: 1.48-16.48, p $=0.009$ ). AFP expression was significantly positively correlated with HGF and c-Met expression. Transwell invasion assay revealed significantly increased cell motility with AFP overexpression. Conclusion: AFP-positivity is a significant negative predictor of overall survival in patients with colorectal cancer, which may be mediated by HGF/c-Met signaling pathway.




\section{Cellular Physiology Cell Physiol Biochem 2018;51:2052-2064

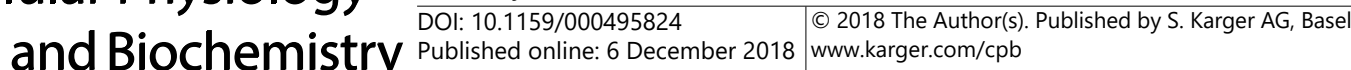

Feng et al.: AFP is a Negative Predictor of Overall Survival

\section{Introduction}

Alpha-fetoprotein (AFP) was first described in 1963 by Abelev et al. and is normally produced in the fetal liver and yolk sac [1]. AFP in human fetal blood rises rapidly from the end of the first trimester and begin to fall after 32 weeks of gestation. After birth, serum AFP level continues to fall with a half-life of 3-4 days, and by the second year of life to the normal range [2-4]. Some tumors were found to produce AFP which lead to an increase in serum AFP levels. Therefore, AFP is considered as a reliable tumor marker in the diagnosis of tumors, such as embryonal testicular tumors, hepatocellular carcinomas, and yolk sac tumors [57]. Apart from these classic tumors, AFP has been detected in several other organs, and recently reported cases of AFP-producing tumors of the stomach [8], pancreas [9], bile duct [10], lung [11], kidney [12], and ovary [13] have increased. Alpha-fetoprotein-producing colorectal cancer (AFPP-CRC) is extremely rarely seen and only 16 cases could be referred to in the English literature to date [14-16]. In 1985, Nakajima [17] first reported a patient of AFP-producing rectal cancer bearing liver and lung metastasis. Since then, scattered cases of AFPP-CRC have been reported, and these case reports showed that it was always associated with later stage, lymph node metastasis, liver metastasis, and dismal prognosis [14]. At present, to our best knowledge, there is no consistent definition for AFPP-CRC. 14 out of these 16 patients had elevated serum levels of preoperative AFP and the tumor cells did not always produce AFP consistently [15].

AFPP-CRC shows aggressive characteristics and is prone to have liver metastasis and lymph node metastasis. Thus, accordingly, AFPP-CRC bears an extremely poor prognosis. However, all previous studies are case reports and the pathogenesis and clinical characteristics of AFPP-CRC remain elusive. To improve understanding of AFPP-CRC, we retrospectively reviewed the clinicopathologic features and prognostic factors of a consecutive series of 78 AFPP-CRC patients in the Fudan University Shanghai Cancer Center. We hypothesized AFPpositivity was a significant negative predictor of overall survival in patients with colorectal cancer, and may be correlated to liver metastasis.

\section{Materials and Methods}

\section{Patients}

Between 2006 and 2016, in the Fudan University Shanghai Cancer Center, 5, 051 patients with histologically confirmed colorectal cancer underwent primary excision. Data was retrieved from patients' in-patient records and pathological reports, and follow-up data was obtained by phone and the out-patient records. Serum AFP was tested in all of these patients preoperatively and was considered as AFP-positive when elevated serum AFP levels ( $>10 \mu \mathrm{g} / \mathrm{L}$ ) were detected. Multiple phases MRI or CT with contrast were done in every case. Patients with hepatic disease, such as chronic hepatitis, fatty liver, or hepatocellular carcinoma, were excluded from this analysis. Patients who had undergone preoperative chemo- or radio chemotherapy were excluded. Finally, 78 patients were identified as AFP-positive. Of 78 patients AFPpositive patients, only 27 cases were available for immunochemically staining in our pathology department. Informed consent had been obtained and this study was approved by the institutional review board of the Fudan University Shanghai Cancer Center.

\section{Immunohistochemistry (IHC)}

Immunohistochemically staining was performed according to standard protocol. Briefly, paraffinembedded samples were cut into $4 \mu \mathrm{m}$ sections and placed on polylysine-coated slides. Paraffin sections were baked overnight at $58^{\circ} \mathrm{C}$, de-paraffinized in xylene, rehydrated through graded ethanol, quenched for endogenous peroxidase activity in $0.3 \%$ hydrogen peroxide at $37^{\circ} \mathrm{C}$ for $15 \mathrm{~min}$, and processed for antigen retrieval by high pressure cooking in citrate antigen retrieval solution $(\mathrm{pH}=6.0)$ for about $10 \mathrm{~min}$. Sections were incubated at $37{ }^{\circ} \mathrm{C}$ for $1.5 \mathrm{~h}$ with rabbit polyclonal antibody against AFP (1:400, Dako, DK-2600 Glostrup, Denmark), HGF (1:100, Proteintech, 26881-1-AP) and c-Met (1:100, Proteintech, 25869-1-AP) in a moist chamber. Immunostaining was performed using the EnVision+System-HRP (AEC) (K4005, Dako, 


\section{Cellular Physiology Cell Physiol Biochem 2018;51:2052-2064 and Biochemistry Published \begin{tabular}{l|l} 
DOI: 10.1159/000495824 & $\begin{array}{l}\text { C) } 2018 \text { The Author(s). Published by S. Karger AG, Basel } \\
\text { www.karger.com/cpb }\end{array}$
\end{tabular}}

Feng et al.: AFP is a Negative Predictor of Overall Survival

Glostrup, Denmark), which resulted in a brown-colored precipitate at the antigen site. Subsequently, sections were counterstained with hematoxylin (Sigma-Aldrich, St Louis, MO, USA) and mounted in a non-aqueous mounting medium. All runs included a no primary antibody control. The immunohistochemically stained tissue sections were scored separately by two pathologists blinded to the clinicopathological parameters. The staining intensity was scored as 0 (negative), 1 (weak), 2 (medium) or 3 (strong). Extent of staining was scored as $0(<5 \%), 1(5-25 \%), 2(26-50 \%), 3(51-75 \%)$ and $4(>75 \%)$ according to the percentages of the positive staining areas in relation to the whole carcinoma area. Scores for staining intensity and percentage positivity of cells were then multiplied to generate the immunoreactivity score (IRS) for each case. Samples having a final staining score of $\leq 4$ were considered to be low and those with score of $>4$ were considered to be high.

\section{Cell culture}

The human colorectal cancer cell lines (RKO, LoVo) were originally purchased from the American Type Culture Collection (Manassas, VA, USA). All cell lines were cultured in medium (DMEM/F12, Hyclone) according to the Defense Technical Information Center recommendation supplemented with $10 \%$ FBS (Gibco, Life Technology, Austria), 1\% penicillin/streptomycin in a humidified 5\% (v/v) atmosphere of CO2 at $37^{\circ} \mathrm{C}$.

\section{RNA extraction, reverse transcription, and qRT-PCR analysis}

Total RNA was isolated from cell lines using TRIzol@ reagent (15596-026, Invitrogen). A PrimeScript ${ }^{\mathrm{TM}}$ RT Master Mix (Perfect Real Time) kit (RR036A, Takara) was used to synthesize first-strand cDNA from total RNA. After that, SYBR Green real-time PCR assays were performed using ABI 7900HT (Applied Biosystems, USA). The expression level of RNA was normalized to the level of GAPDH. The primers for qRT-PCR analysis were synthesized by Huagene (Shanghai, PRC). qRT-PCR was used to detect AFP expression, using forward primer (5' - TGCAGCCAAAGTGAAGAGGGAAGA -3') and reverse primer (5'- CATAGCGAGCAGCCCAAAGAAGAA -3'). GAPDH was used as the internal reference (forward primer: 5'- GCACCGTCAAGGCTGAGAAC -3'; reverse primer: 5'- TGGTGAAGACGCCAGTGGA -3'). The RQ value was applied to analyze the relative changes in gene expression.

\section{Western blot analysis}

Total proteins from cells were extracted in lysis buffer (Pierce, Thermo Scientifc, USA), and the concentration was determined using the BCA protein assay kit (Pierce, Thermo Scientifc, USA). Cell lysates were electrophoresed on SDS-polyacrylamide gels and transferred onto polyvinylidene fluoride membranes (Millipore, Billerica, MA, USA). Membranes were blocked with 5\% BSA in TBST buffer $(0.1 \%$ Tween-20, 20 $\mathrm{mM}$ Tris- $\mathrm{HCl} \mathrm{pH} 7.5$, and $140 \mathrm{mM} \mathrm{NaCl}$ ) and probed with primary antibodies (GAPDH from Abcam, and AFP from Affinity Biosciences) at 1:1000 dilution, followed by secondary antibody-horseradish peroxidase conjugate (from Affinity Biosciences). Bounded proteins were visualized using ECL (Pierce, Thermo Scientifc, USA) and detected using a BioImaging System.

\section{CCK8 assay}

We seeded 96-well plates with each group of cells at a density of 2000 cells per well and cultured for $24,48,72,96$, and $120 \mathrm{~h}$, respectively. $10 \mu \mathrm{L}$ of CCK8 solution was added to each well and incubated for $2 \mathrm{~h}$ at $37^{\circ} \mathrm{C}$. Then, cell viability of each well was measured spectrophotometrically at $450 \mathrm{~nm}$. The cell viability of different groups at each measuring time point was compared.

\section{In vitro migration assay}

The migration assay was conducted in a 24-well plate with Transwell chamber (Costar, Cambridge, MA) (BD Biosciences, San Jose, CA, USA). Briefly, $200 \mu \mathrm{L}$ of cell suspensions $\left(5 \times 10^{4}\right.$ cells) prepared in serumfree medium was loaded in the upper well of the chamber, while $500 \mu \mathrm{L}$ of medium containing $10 \%$ FBS was placed in the lower well as a chemoattractant stimulus. The chamber was incubated for $48 \mathrm{~h}$ at $37^{\circ} \mathrm{C}$, and the nonmigratory cells in the upper chamber were removed with a cotton tip. The migrated cells on the bottom surface of the filter were fixed with $4 \%$ paraformaldehyde, stained with crystal violet, and then counted under a microscope in five randomly selected fields at $\times 100$ magnification.

\section{KARGER}




\section{Statistical Analysis}

Propensity score matching (PSM) for reduction of intergroup disparities was performed using R 2.15.3 software. Variables included in the PSM were age, location, pT, pN, M stage, vascular invasion and neural invasion. AFP-positive patients $(n=75)$ were matched to AFP-negative patients $(n=75)$ using the nearest neighbor matching within a caliper of 0.001 . The Chi-square test and Fisher's exact analysis were performed to compare clinicopathological factors between each group. Five-year survival rates were calculated by Kaplan-Meier method and compared using the log-rank test. Univariate and multivariate survival analyses were conducted to identify independently significant variables using Cox proportional hazards model. The correlation of AFP and HGF/c-Met was conducted by Spearman method. The accepted level of significance was $\mathrm{P}<0.05$. Statistical analyses and graphics were performed with the SPSS 22.0 statistical package, GraphPad Prism software and the R 2.15.3 software.

\section{Results}

\section{Baseline characteristics}

As shown in Table 1, direct comparison between AFPP-CRC ( $\mathrm{n}=78$ ) and AFPN-CRC $(n=4,973)$ patients revealed significant differences in age $(p=0.034)$, location $(p=0.033)$, pathological grading $(\mathrm{p}=0.025)$, $\mathrm{pT}(\mathrm{p}=0.001)$, M stage $(\mathrm{p}<0.001)$, TNM stage $(\mathrm{p}<0.001)$, and liver metastasis $(\mathrm{p}<0.001)$. Patients with AFPP-CRC had a significantly higher incidence of younger age, rectum disease, poorly differentiated disease, advanced TNM stage, and liver metastasis. There were no differences for gender, histology type, $\mathrm{pN}$, vascular invasion, neural invasion, and the number of retrieved lymph nodes. After PSM, all these baseline characteristics were well-balanced and no statistical significance was achieved.

Table 1. Baseline characteristics of AFP-positive and -negative patients before and after propensity score matching (PSM). P values are from Chi-square test and were significant at < 0.05. AFP: $\alpha$-fetoprotein; TNM: Tumor, nodes, metastasis; LNH: lymph node harvested

\begin{tabular}{|c|c|c|c|c|c|c|c|}
\hline \multirow{3}{*}{ Variables } & \multirow{3}{*}{ Subgroup } & \multicolumn{6}{|c|}{ No. (\%) of patients } \\
\hline & & \multicolumn{2}{|c|}{ Total Patients $(n=5,051)$} & \multicolumn{4}{|c|}{ After PSM $(n=150)$} \\
\hline & & $\begin{array}{c}\text { AFP-negative } \\
(n=4,973)\end{array}$ & $\begin{array}{l}\text { AFP-positive } \\
(\mathrm{n}=78)\end{array}$ & $\mathrm{P}$ & $\begin{array}{c}\text { AFP-negative } \\
(n=75)\end{array}$ & $\begin{array}{c}\text { AFP-positive } \\
(n=75)\end{array}$ & $\mathrm{P}$ \\
\hline \multirow[t]{2}{*}{ Gender } & Male & $2,938(59.1)$ & $47(60.3)$ & \multirow{2}{*}{0.834} & $47(62.7)$ & $46(61.3)$ & \multirow{2}{*}{0.866} \\
\hline & Female & $2,035(40.9)$ & $31(39.7)$ & & $28(37.3)$ & $29(38.7)$ & \\
\hline \multirow[t]{2}{*}{ Age } & $<60$ & $2,588(52.0)$ & $50(64.1)$ & \multirow{2}{*}{0.034} & $48(64.0)$ & $48(64.0)$ & \multirow{2}{*}{1.000} \\
\hline & $\geq 60$ & $2,385(48.0)$ & $28(35.9)$ & & $27(36.0)$ & $27(36.0)$ & \\
\hline \multirow[t]{2}{*}{ Location } & Colon & $2,200(44.2)$ & $26(33.3)$ & \multirow{2}{*}{0.033} & $24(32.0)$ & $24(32.0)$ & \multirow{2}{*}{1.00} \\
\hline & Rectum & $2,773(55.8)$ & $52(66.7)$ & & $51(68.0)$ & $51(68.0)$ & \\
\hline \multirow[t]{3}{*}{ Pathological grading } & Poorly differentiated & $364(7.3)$ & $10(12.8)$ & & $2(2.7)$ & $6(8.0)$ & \multirow{3}{*}{0.097} \\
\hline & Moderately differentiated & $4,223(84.9)$ & $67(85.9)$ & \multirow[t]{2}{*}{0.025} & $68(90.7)$ & $68(90.7)$ & \\
\hline & Well differentiated & $386(7.8)$ & $1(1.3)$ & & $5(6.7)$ & $1(1.3)$ & \\
\hline \multirow{3}{*}{ Histology type } & Adenocarcinoma & $4,636(93.2)$ & $71(91.0)$ & \multirow{3}{*}{0.723} & $74(98.7)$ & $68(90.7)$ & \multirow{3}{*}{0.090} \\
\hline & Mucinous adenocarcinoma & $298(6.0)$ & $6(7.7)$ & & $1(1.3)$ & $6(8.0)$ & \\
\hline & Signet ring cell carcinoma & $39(0.8)$ & $1(1.3)$ & & $0(0)$ & $1(1.3)$ & \\
\hline \multirow[t]{4}{*}{ pT } & pT1 & $263(5.3)$ & $5(6.4)$ & \multirow{4}{*}{0.001} & $5(6.7)$ & $5(6.7)$ & \multirow{4}{*}{1.000} \\
\hline & pT2 & $872(17.5)$ & $11(14.1)$ & & $11(14.7)$ & $11(14.7)$ & \\
\hline & pT3 & $2,443(49.1)$ & $54(69.2)$ & & $52(69.3)$ & $52(69.3)$ & \\
\hline & pT4 & $1,395(28.1)$ & $8(10.3)$ & & $7(9.3)$ & $7(9.3)$ & \\
\hline \multirow[t]{3}{*}{$\mathrm{pN}$} & pNO & $2,491(50.1)$ & $42(53.8)$ & \multirow{3}{*}{0.805} & $40(53.3)$ & $40(53.3)$ & \multirow{3}{*}{1.000} \\
\hline & pN1 & $1,307(26.3)$ & $19(24.4)$ & & $19(25.3)$ & $19(25.3)$ & \\
\hline & $\mathrm{pN} 2$ & $1,175(23.6)$ & $17(21.8)$ & & $16(21.3)$ & $16(21.3)$ & \\
\hline \multirow[t]{2}{*}{ M stage } & M0 & $4,477(90.0)$ & $51(65.4)$ & $<0.001$ & $51(68.0)$ & $51(68.0)$ & 1.000 \\
\hline & M1 & $496(10.0)$ & $27(34.6)$ & $<0.001$ & $24(32.0)$ & $24(32.0)$ & 1.000 \\
\hline TNM stage & I & $842(17.0)$ & $7(9.0)$ & & $7(9.3)$ & $7(9.3)$ & \\
\hline & II & $1,429(28.7)$ & $22(28.2)$ & & $21(28.0)$ & $22(29.3)$ & \\
\hline & III & $2,206(44.4)$ & $22(28.2)$ & $<0.001$ & $23(30.7)$ & $22(29.3)$ & .997 \\
\hline & IV & $496(10.0)$ & $27(34.6)$ & & $24(32.0)$ & $24(32.0)$ & \\
\hline Liver metastasis & Yes & $377(7.6)$ & $24(30.8)$ & & $18(24.0)$ & $22(29.3)$ & 460 \\
\hline & No & $4,596(92.4)$ & $54(69.2)$ & $<0.001$ & $57(76.0)$ & $53(70.7)$ & .460 \\
\hline Vascular invasion & Yes & $1,303(26.2)$ & $18(23.1)$ & & $18(24.0)$ & $18(24.0)$ & 1000 \\
\hline & No & $3,670(73.8)$ & $60(76.9)$ & 0.533 & $57(76.0)$ & $57(76.0)$ & 1.000 \\
\hline Neural invasion & Yes & $1,028(20.7)$ & $16(20.5)$ & & $14(18.7)$ & $14(18.7)$ & 1000 \\
\hline & No & $3,945(79.3)$ & $62(79.5)$ & 0.973 & $61(81.3)$ & $61(81.3)$ & 1.000 \\
\hline LNH & $<12$ & $1,073(21.6)$ & $20(25.6)$ & & $15(20.0)$ & $19(25.3)$ & 0.435 \\
\hline & $\geq 12$ & $3,900(78.4)$ & $58(74.4)$ & 0.387 & $60(80.0)$ & $56(74.7)$ & 0.435 \\
\hline
\end{tabular}


Log-rank test comparing overall survival between two cohorts

During follow-up, 19 patients (24.4\%) in the AFPP-CRC group died comparing to 607 patients (12.3\%) in the AFPN-CRC group. Log-rank test confirmed overall survival (OS) was significantly different between the two groups $(\mathrm{p}=0.001)$. Five-year survival rate in the unmatched cohort was $78.5 \%$ for AFPN-CRC and $64.7 \%$ for AFPP-CRC patients. After PSM, OS was still significantly different between the two groups $(\mathrm{p}=0.01)$. Five-year survival rate was $86.9 \%$ for AFPN-CRC and $63.9 \%$ for AFPP-CRC patients. OS curves for the unmatched and PSM-groups were shown in Fig. 1.

\section{Cox regression analysis on overall survival of the unmatched and PSM-cohorts}

In univariate analysis of the unmatched groups, older age $(\mathrm{p}=0.012)$, poorly differentiated grade $(p<0.001)$, signet ring cell carcinoma $(p<0.001)$, presence of vascular invasion or neural invasion ( $\mathrm{p}<0.001)$, inadequate number of lymph nodes harvested $(\mathrm{p}=$ $0.002)$, AFP positivity $(\mathrm{p}=0.001)$ and advanced TNM-stage $(\mathrm{p}<0.001)$ were significantly negatively related to $O S$. In the multivariate model, all these variables remained significant except for histology type $(p=0.492)$ and AFP positivity ( $p=0.097)$. After PSM, AFP-positivity was one of the strongest predictors of OS in the multivariate model (HR 4.11, CI 95\%: 1.43$11.76, \mathrm{p}=0.009)$. Except for AFP positivity, only TNM stage $(\mathrm{p}=0.002)$ was significantly related to OS. The results were displayed in Table 2 .

\section{Cox regression analysis on OS of AFPP-CRC patients}

We further investigated prognostic factors affecting prognosis in AFPP-CRC patients, as shown in Table 3. Univariate and multivariate analyses revealed that the presence of liver metastasis was the only independent prognostic factor (HR 4.95, CI 95\%: 1.48-16.48; P = $0.009)$.

\section{Immunohistochemically-related results}

Of 78 patients with elevated serum AFP levels, only 27 patients were available for immunohistochemically staining. Based on the staining results of AFP (see Fig. 2), patients were classified as AFP low (11 cases, $40.7 \%$ ) and AFP high (16 cases, 59.3\%), staining results of HGF and c-Met were provided in Supporting Information Fig. 3 and Fig. 4. We plotted Kaplan-Meier curve depending on IHC subgroup (see Fig. 5), and found survival rate of the AFP high group was significantly lower than the AFP low group ( $p=0.049)$, and survival rate

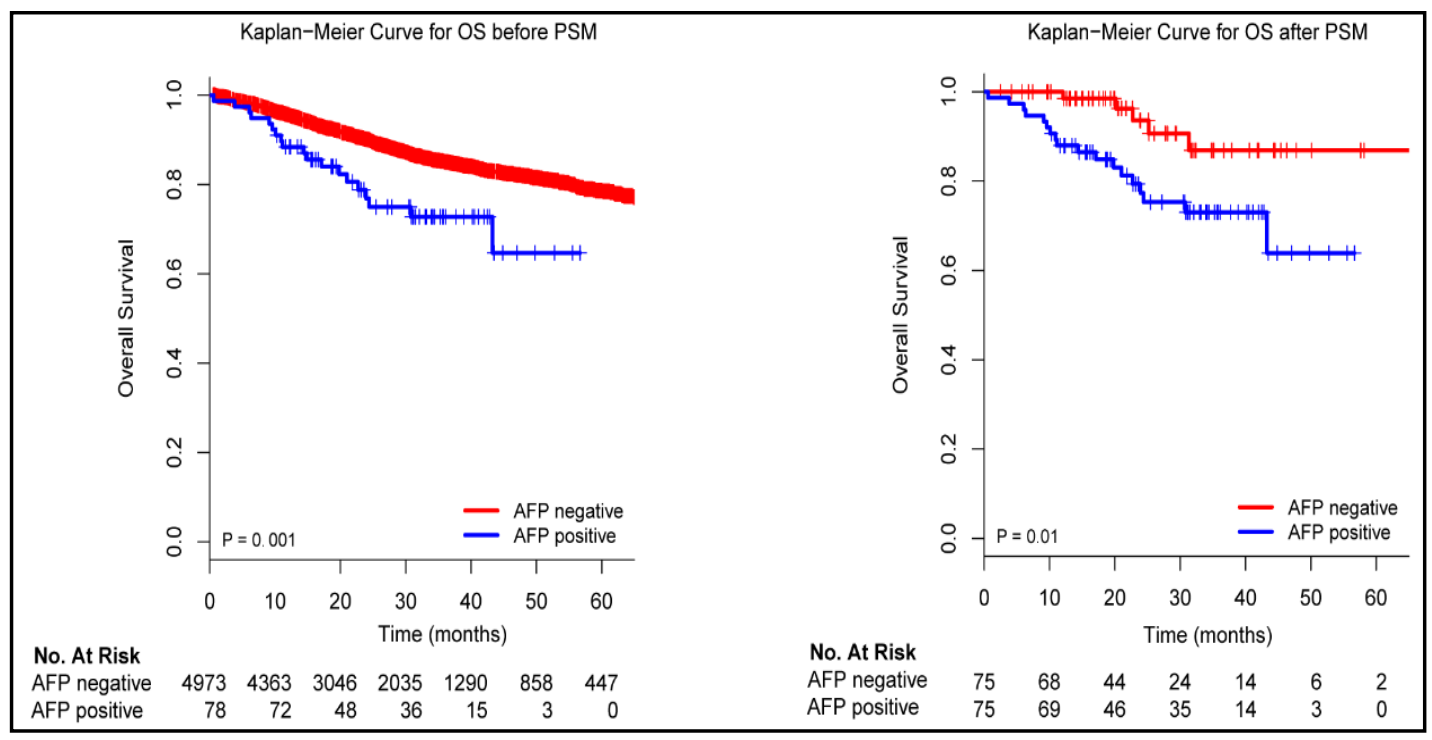

Fig. 1. Overall survival (OS) related to AFP-producing colorectal cancer before and after propensity score matching (PSM). 
Table 2. Uni- and multivariate analyses for variables related to overall survival before and after PSM. Uni- and multivariate survival analysis were performed using Cox's proportional hazard model. AFP: $\alpha$-fetoprotein; TNM: Tumor, nodes, metastasis; LNH: lymph node harvested; PSM: propensity score matching

\begin{tabular}{|c|c|c|c|c|c|c|c|c|c|}
\hline \multirow{3}{*}{ Variables } & \multirow{3}{*}{ Subgroup } & \multicolumn{4}{|c|}{ Total patients $(\mathrm{n}=5,051)$} & \multicolumn{4}{|c|}{ After PSM (n=150) } \\
\hline & & \multicolumn{2}{|c|}{ Univariable } & \multicolumn{2}{|c|}{ Multivariable } & \multicolumn{2}{|c|}{ Univariable } & \multicolumn{2}{|c|}{ Multivariable } \\
\hline & & Hazard ratio & $P$ & Hazard ratio & $P$ & Hazard ratio & $P$ & Hazard ratio & $P$ \\
\hline Gender & $\begin{array}{c}\text { Male } \\
\text { Female }\end{array}$ & $\begin{array}{c}1 \\
1.03(0.88,1.21)\end{array}$ & 0.686 & & & $\begin{array}{c}1 \\
0.90(0.39,2.09)\end{array}$ & 0.808 & & \\
\hline Age & $\begin{array}{l}<60 \\
>60\end{array}$ & $\begin{array}{c}1 \\
1 \\
122(105\end{array}$ & 0.012 & $\begin{array}{l}1 \\
145171)\end{array}$ & $<0.001$ & 1 & 0.442 & & \\
\hline Location & Colon & $\begin{array}{c}1.2(1.05,1.45) \\
1\end{array}$ & 0.061 & & & 1 & 0.417 & & \\
\hline Pathological grading & Poorly differentiated & $\begin{array}{c}0.86(0.74,1.01) \\
1\end{array}$ & & 1 & & $\begin{array}{c}0.71(0.31,1.64 \\
1\end{array}$ & & & \\
\hline Histology type & Adenocarcinoma & $0.16(0.10,0.27)$ & & $0.35(0.21,0.59)$ & & $\begin{array}{l}0 \\
1\end{array}$ & & & \\
\hline & Mucinous adenocarcinoma & $1.28(0.95,1.71)$ & $<0.001$ & & & $0.70(0.09,5.20)$ & 0.042 & & \\
\hline TNM stage & I & $\begin{array}{c}0.12(1.04,0.01) \\
1\end{array}$ & & 1 & & $\begin{array}{c}13.40(1 . / 2,105.34) \\
1\end{array}$ & & 1 & \\
\hline & $\begin{array}{l}\text { II } \\
\text { III }\end{array}$ & $\begin{array}{c}2.63(1.58,4.39) \\
8.49(5.29,13.63)\end{array}$ & $<0.001$ & $\begin{array}{c}2.42(1.45,4.06) \\
5.94(3.67,9.622)\end{array}$ & $<0.001$ & $\begin{array}{l}0.47(0.08,2.82) \\
0.49(0.08,2.94)\end{array}$ & 0.001 & $\begin{array}{l}0.30(0.05,1.88) \\
0.33(0.05,2.27)\end{array}$ & 0.002 \\
\hline & IV & $18.64(11.42,30.41)$ & & $12.84(7.75,21.25)$ & & $3.40(0.77,15.04)$ & & $2.75(0.53,14.2)$ & \\
\hline $\operatorname{AFP}(\mu \mathrm{g} / \mathrm{L})$ & $\begin{array}{l}<10 \\
\geq 10\end{array}$ & $\begin{array}{c}1 \\
2.12(1.35,3.36)\end{array}$ & 0.001 & & & $\begin{array}{c}1 \\
3.43(1.27,9.24)\end{array}$ & 0.015 & $\begin{array}{c}1 \\
4.11(1.43,11.76)\end{array}$ & 0.009 \\
\hline Vascular invasion & $\begin{array}{l}\text { Yes } \\
\text { No }\end{array}$ & $\begin{array}{c}1 \\
2.96(2.53,3.46)\end{array}$ & $<0.001$ & $\begin{array}{c}1 \\
1.73(1.46,2.05)\end{array}$ & $<0.001$ & $\begin{array}{c}1 \\
1.61(0.66,3.94)\end{array}$ & 0.294 & & \\
\hline Neural invasion & $\begin{array}{l}\text { Yes } \\
\text { No }\end{array}$ & $\begin{array}{c}1 \\
2.24(1.90,2.64)\end{array}$ & $<0.001$ & $\begin{array}{c}1 \\
1.29(1.08,1.54)\end{array}$ & 0.005 & $\begin{array}{c}1 \\
1.99(0.78,5.07)\end{array}$ & 0.152 & & \\
\hline LNH & $\begin{array}{l}<12 \\
\geq 12\end{array}$ & $\begin{array}{c}1 \\
0.76(0.64,0.91)\end{array}$ & 0.002 & $\begin{array}{c}1 \\
0.77(0.64,0.92)\end{array}$ & 0.003 & $\begin{array}{c}1 \\
0.94(0.37,2.40)\end{array}$ & 0.901 & & \\
\hline
\end{tabular}

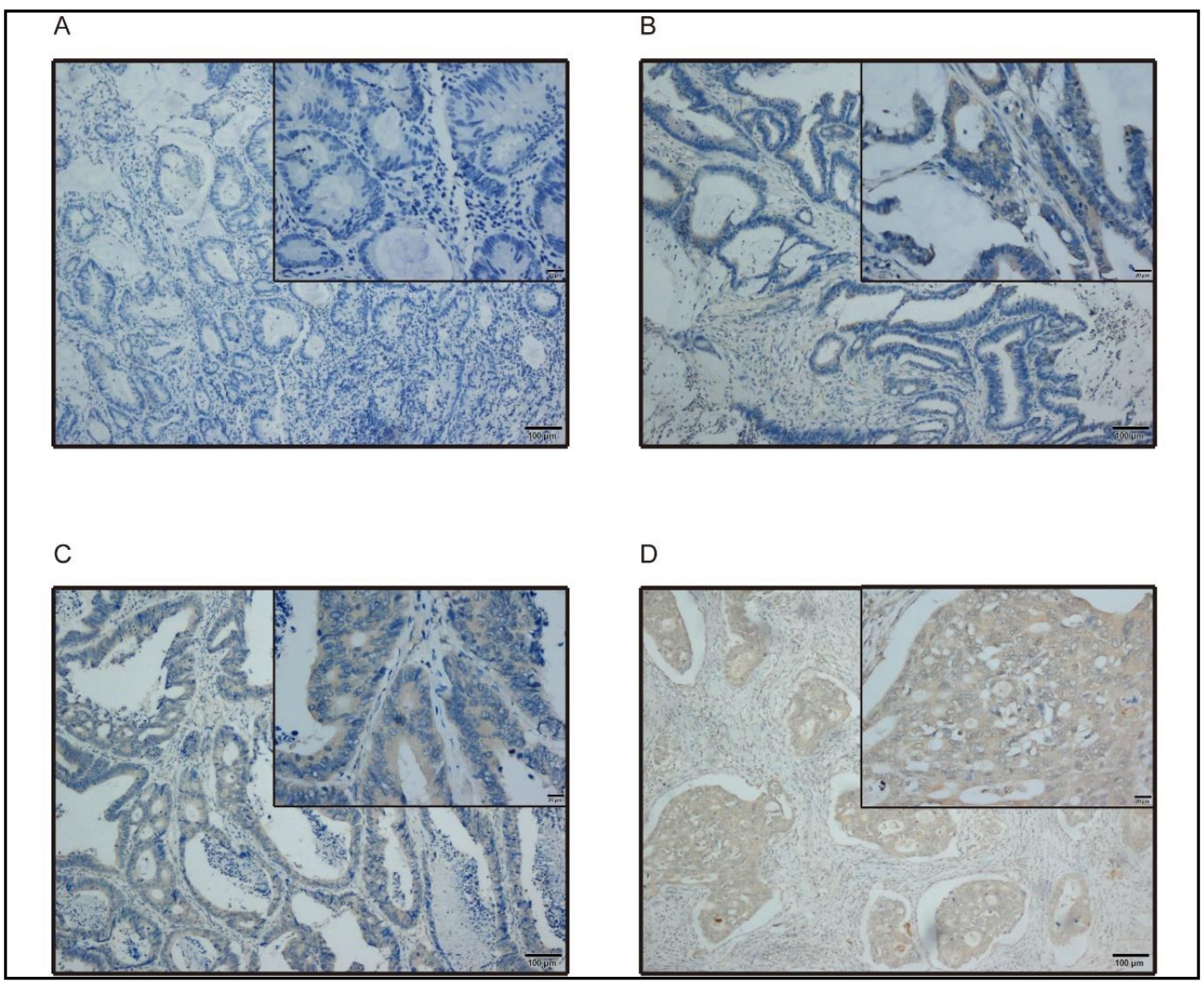

Fig. 2. Immunohistochemically reactivity for alpha-fetoprotein (AFP) in colorectal cancer samples. AFP displayed a cytoplasm-accentuated expression, which was often accompanied by a membrane expression. negative tumor staining (A); weak tumor staining (B); medium tumor staining (C); strong tumor staining (D).

\section{KARGER}


of the HGF high group was significantly lower than the HGF low group ( $\mathrm{p}=$ $0.036)$, while survival rate of the c-Met high and c-Met low group didn't reach statistically significance $(\mathrm{p}=0.16)$. We further compared the baseline characteristics of AFP high and AFP low group, and found only liver metastasis was significantly different between the two groups $(\mathrm{p}=0.013$ ) (as shown in Table 4). AFP expression was significantly positively correlated with HGF (correlation coefficient of spearman $=0.601$ ) and c-Met (correlation coefficient of spearman $=$ 0.558) expression.

\begin{tabular}{|c|c|c|c|c|c|}
\hline \multirow{3}{*}{ Variables } & \multirow{3}{*}{ Subgroup } & \multicolumn{4}{|c|}{ Total Patients ( $\mathrm{n}=78$ ) } \\
\hline & & \multicolumn{2}{|c|}{ Univariable } & \multicolumn{2}{|l|}{ Multivariable } \\
\hline & & Hazard ratio & $P$ & Hazard ratio & $\mathrm{P}$ \\
\hline Gender & Male & $\begin{array}{c}1 \\
140(0575)\end{array}$ & 0.463 & & \\
\hline Age & $<60$ & & & & \\
\hline & $\geq 60$ & $0.44(0.15,1.32)$ & 0.142 & & \\
\hline Location & $\begin{array}{l}\text { Colon } \\
\text { Rectum }\end{array}$ & $\begin{array}{c}1 \\
0.62(0.25156)\end{array}$ & 0.311 & & \\
\hline Pathological grading & $\begin{array}{l}\text { Rectum } \\
\text { Poorly differentiated }\end{array}$ & $0.62(0.25,1.56)$ & & & \\
\hline & $\begin{array}{l}\text { Moderately differentiated } \\
\text { Well differentiated }\end{array}$ & $0.93(0.27,3.22)$ & 0.993 & & \\
\hline Histology type & Adenocarcinoma & 1 & & & \\
\hline & $\begin{array}{l}\text { Mucinous adenocarcinoma } \\
\text { Signet ring cell carcinoma }\end{array}$ & $\begin{array}{c}0.50(0.07,3.75) \\
7.60(0.96,60.15)\end{array}$ & 0.118 & & \\
\hline pT & pT1 & 1 & & & \\
\hline & pT2 & $6.41(0.57,72.56)$ & 0.466 & & \\
\hline & pT3 & $\begin{array}{l}2.18(0.20,24.26) \\
3.22(0.42 .2477)\end{array}$ & & & \\
\hline $\mathrm{pN}$ & pNo & 1 & & & \\
\hline & $\mathrm{pN} 1$ & $0.73(0.20,2.65)$ & 0.460 & & \\
\hline & $\mathrm{pN} 2$ & $1.64(0.59,4.52)$ & & & \\
\hline Liver metastasis & Yes & 1 & 0.002 & & 0.009 \\
\hline Vascular invasion & $\begin{array}{l}\text { No } \\
\text { Yes }\end{array}$ & $4.11(1.64,10.28)$ & & $4.95(1.48,16.48)$ & \\
\hline & No & $1.65(0.63,4.37)$ & 0.310 & & \\
\hline Neural invasion & Yes & & 0.184 & & \\
\hline & $\begin{array}{l}\text { No } \\
<12\end{array}$ & $1.93(0.73,5.08)$ & & & \\
\hline LNH & $\begin{array}{l}<12 \\
\geq 12\end{array}$ & $\begin{array}{c}1 \\
1.08(0.38,3.03)\end{array}$ & 0.884 & & \\
\hline
\end{tabular}

Table 3. Uni- and multivariate analyses for variables related to overall survival in AFP-positive colorectal cancer. Uni- and multivariate survival analysis were performed using Cox's proportional hazard model. AFP: $\alpha$-fetoprotein; TNM: Tumor, nodes, metastasis
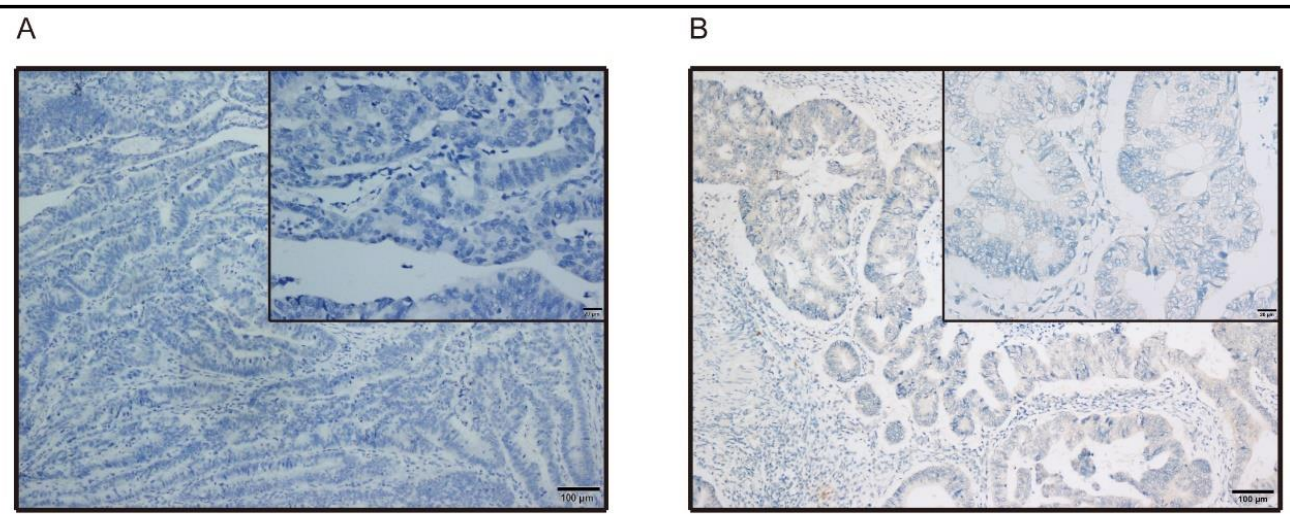

C

D
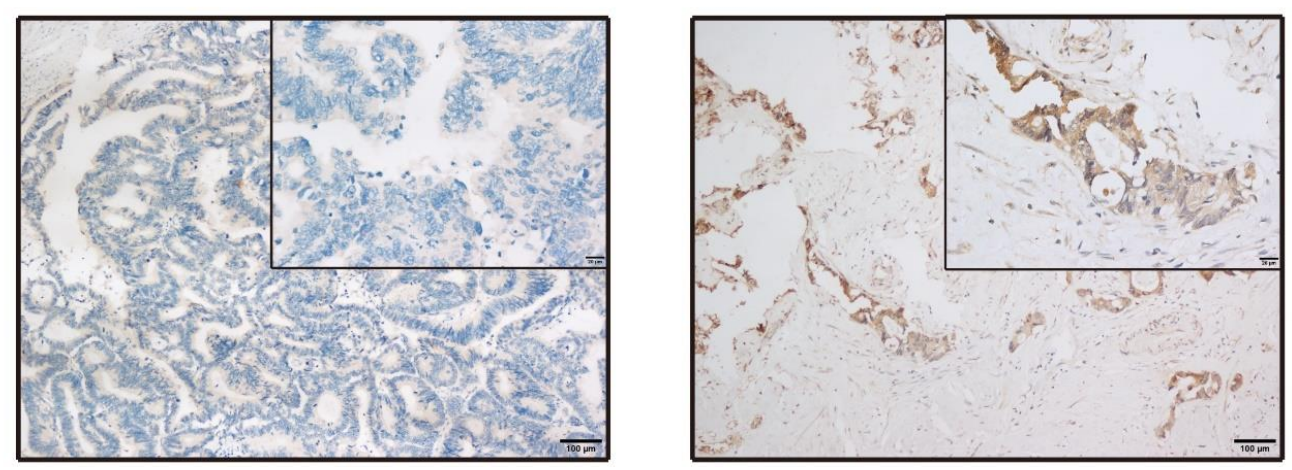

Fig. 3. Immunohistochemically reactivity for hepatocyte growth factor (HGF) in colorectal cancer samples. HGF displayed a cytoplasm-accentuated expression. negative tumor staining(A); weak tumor staining(B); medium tumor staining(C); strong tumor staining(D). 


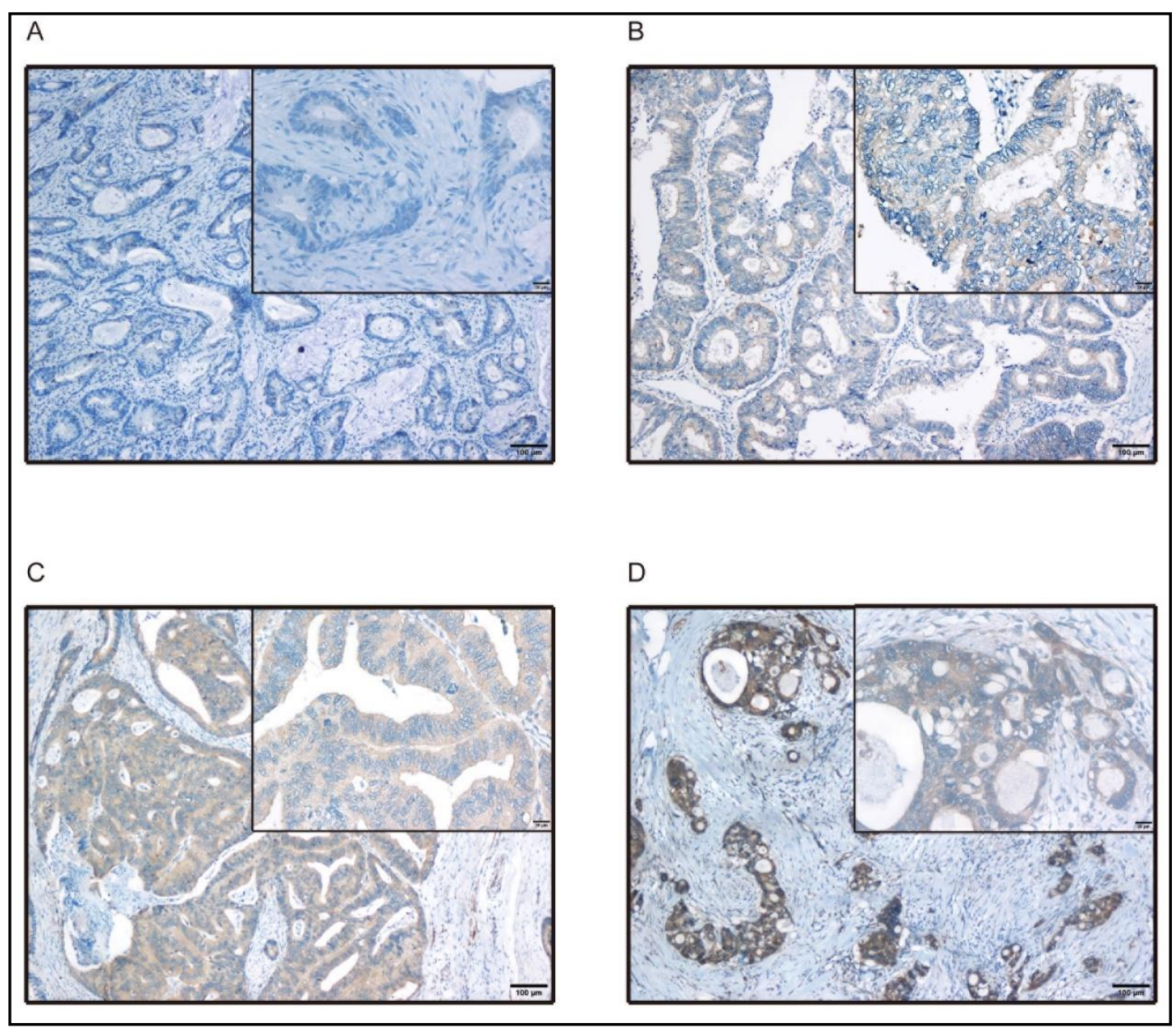

Fig. 4. Immunohistochemically reactivity for met proto-oncogene (c-Met) in colorectal cancer samples. c-Met displayed a cytoplasm-accentuated expression, which was often accompanied by a membrane expression. negative tumor staining(A); weak tumor staining(B); medium tumor staining(C); strong tumor staining(D).

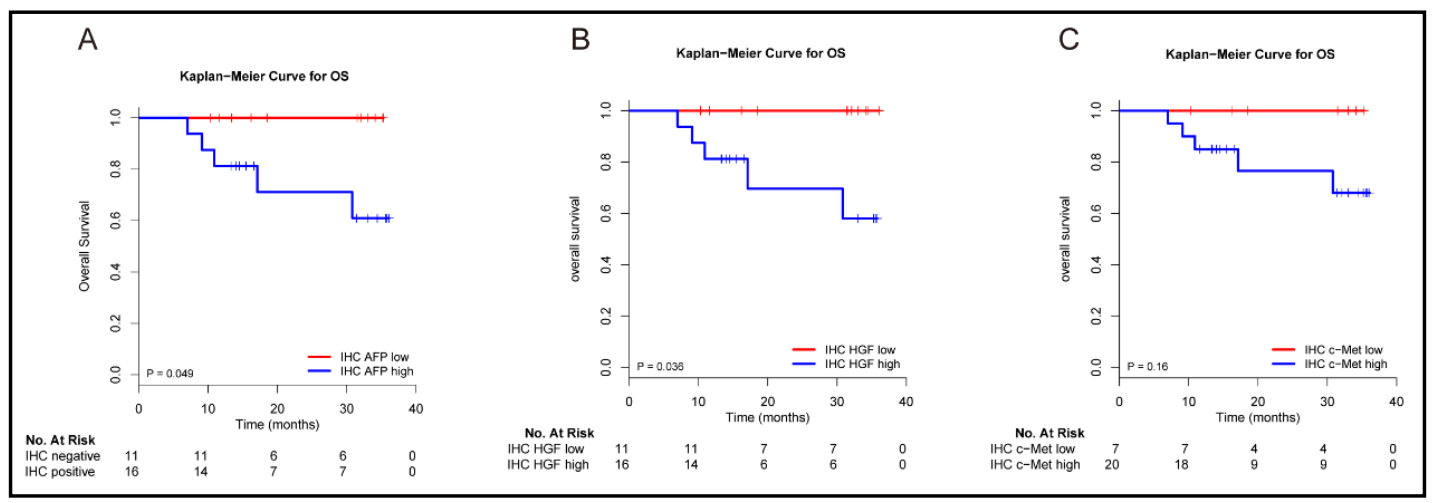

Fig. 5. Overall survival (OS) related to Immunohistochemical AFP, HGF and c-Met expression in colorectal cancer. 
AFP promotes the migration of colorectal cancer cells in vitro

To determine the oncogenic function of AFP, we established transient AFP overexpressing in LOVO and RKO cells, and overexpression of AFP in the cells were determined by RT-PCR and western blot (Fig. 6A). CCK8 assay (Fig. $6 B)$ showed cell growth rates in AFP-transfected cells and the control cells were not significantly different $(\mathrm{p}>$ 0.05). Transwell invasion assay (Fig. 6C) revealed significantly increased cell motility with AFP overexpression, as compared with control cells $(\mathrm{p}<0.05)$.

\section{Discussion}

Elevated levels of AFP, usually associated with hepatocellular carcinoma or embryonic cell carcinoma, have also been reported in tumors of several other organs, such as lung, kidney, ovary, and gastrointestinal tract [8-13]. However, AFPP-CRC are extremely rarely seen. The reported cases of AFPP-CRC have generally occurred in middleaged to older men with the rectum most commonly affected. Most reported cases of AFPPCRC had very poor prognosis due to liver or lymph node metastases at the time of diagnosis, and the serum AFP level is usually as high as several-thousand nanograms per milliliter [14]. Therefore, AFP could be considered as a potential marker for tumor activity and a predictor for survival.

Several studies focusing on AFP-producing gastric cancer (AFP-GC) have confirmed the aggressive clinical course and poorer prognosis of this unique subtype [18-21]. Interestingly, there are similarities in AFPP-CRC and AFP-GC considering both groups rapidly progress and frequently metastasize to the liver. There is no standardized definition for AFPGC so far. M. Inoue et al. included only patients with a preoperative AFP level $>40 \mu \mathrm{g} / \mathrm{L}$ or raised preoperative AFP level $(10-39 \mu \mathrm{g} / \mathrm{L})$ with tumor biopsy positive for AFP [20]. Hirajima defined AFP positivity based on the immunohistochemical result irrespective of AFP levels [22]. Another analysis from Liu et al. combined immunohistochemical staining and preoperative serum AFP levels [21]. Reim et al. [19] included all patients with an AFP level $>10 \mu \mathrm{g} / \mathrm{L}$, irrespective of the biopsy result, and this study demonstrates no statistical difference in OS between patients with positive immunohistochemical staining or just AFP elevation over $10 \mu \mathrm{g} / \mathrm{L}$. Therefore, our study used preoperative elevation of AFP (>10 $\mu \mathrm{g} / \mathrm{L})$ as a description of AFPP-CRC. Further studies are merited to define a clear definition of AFPP-CRC as a distinct clinical entity.
Table 4. Baseline characteristics of immunochemically AFP low and AFP high patients. $\mathrm{P}$ values are from Chi-square test and were node harvested

\begin{tabular}{|c|c|c|c|c|}
\hline \multirow{2}{*}{ Variables } & \multirow{2}{*}{ Subgroup } & \multicolumn{3}{|c|}{$\begin{array}{l}\text { No. }(\%) \text { of patients } \\
\text { Total Patients }(n=27)\end{array}$} \\
\hline & & $\begin{array}{l}\text { AFP-low } \\
(n=11)\end{array}$ & $\begin{array}{l}\text { AFP-high } \\
(\mathrm{n}=16)\end{array}$ & $\mathrm{P}$ \\
\hline \multirow[t]{2}{*}{ Gender } & Male & $8(72.7)$ & $10(62.5)$ & \multirow{2}{*}{0.580} \\
\hline & Female & $3(27.3)$ & $6(37.5)$ & \\
\hline \multirow[t]{2}{*}{ Age } & $<60$ & $6(54.5)$ & $8(50.0)$ & \multirow{2}{*}{0.816} \\
\hline & $\geq 60$ & $5(45.5)$ & $8(50.0)$ & \\
\hline \multirow[t]{2}{*}{ Location } & Colon & $5(45.5)$ & $5(31.3)$ & \multirow{2}{*}{0.453} \\
\hline & Rectum & $6(54.5)$ & $11(68.8)$ & \\
\hline \multirow[t]{3}{*}{ Pathological grading } & Poorly differentiated & $2(18.2)$ & $3(18.8)$ & \multirow{3}{*}{0.695} \\
\hline & Moderately differentiated & $9(81.8)$ & $12(75.0)$ & \\
\hline & Well differentiated & $0(0)$ & $1(6.3)$ & \\
\hline \multirow{3}{*}{ Histology type } & Adenocarcinoma & $10(90.9)$ & $14(87.5)$ & \multirow{3}{*}{0.782} \\
\hline & Mucinous adenocarcinoma & $1(9.1)$ & $2(12.5)$ & \\
\hline & Signet ring cell carcinoma & $0(0)$ & $0(0)$ & \\
\hline \multirow[t]{4}{*}{ pT } & pT1 & $2(18.2)$ & $0(0)$ & \multirow{4}{*}{0.319} \\
\hline & pT2 & $1(9.1)$ & $3(18.8)$ & \\
\hline & pT3 & $7(63.6)$ & $12(75.0)$ & \\
\hline & pT4 & $1(9.1)$ & $1(6.3)$ & \\
\hline \multirow[t]{3}{*}{$\mathrm{pN}$} & $\mathrm{pNO}$ & $5(45.5)$ & $8(50.0)$ & \multirow{3}{*}{0.961} \\
\hline & $\mathrm{pN} 1$ & $4(36.4)$ & $5(31.3)$ & \\
\hline & $\mathrm{pN} 2$ & $2(18.2)$ & $3(18.8)$ & \\
\hline \multirow[t]{2}{*}{ M stage } & M0 & $9(81.8)$ & $7(43.8)$ & \multirow{2}{*}{0.109} \\
\hline & M1 & $2(18.2)$ & $9(56.3)$ & \\
\hline \multirow[t]{4}{*}{ TNM stage } & I & $1(9.1)$ & $1(6.3)$ & \multirow{4}{*}{0.244} \\
\hline & II & $3(27.3)$ & $3(18.8)$ & \\
\hline & III & $5(45.5)$ & $3(18.8)$ & \\
\hline & IV & $2(18.2)$ & $9(56.3)$ & \\
\hline \multirow[t]{2}{*}{ Liver metastasis } & Yes & $1(9.1)$ & $9(56.3)$ & \multirow{2}{*}{0.013} \\
\hline & No & $10(90.0)$ & $7(43.8)$ & \\
\hline \multirow[t]{2}{*}{ Vascular invasion } & Yes & $2(18.2)$ & $6(37.5)$ & \multirow{2}{*}{0.280} \\
\hline & No & $9(81.8)$ & $10(62.5)$ & \\
\hline \multirow[t]{2}{*}{ Neural invasion } & Yes & $1(9.1)$ & $4(25.0)$ & \multirow{2}{*}{0.296} \\
\hline & No & $10(90.0)$ & $12(75.0)$ & \\
\hline \multirow[t]{2}{*}{ LNH } & $<12$ & $2(18.2)$ & $3(18.8)$ & \multirow{2}{*}{0.970} \\
\hline & $\geq 12$ & $9(81.8)$ & $13(81.3)$ & \\
\hline
\end{tabular}


Fig. 6. AFP promotes the migration of colorectal cancer cells in vitro. Effect of overexpression of AFP in RKO and LOVO cells analyzed by Western blot and RT-PCR (A). Ectopic expression of AFP did not stimulate cell proliferation as determined by CCK8 assays (B). AFP is associated with migration ability. Overexpression of AFP promotes the migration of RKO and LOVO cells. Scale bars $=100 \mu \mathrm{m}$ (C). Data represent the mean \pm SD and are representative of three independent experiments.

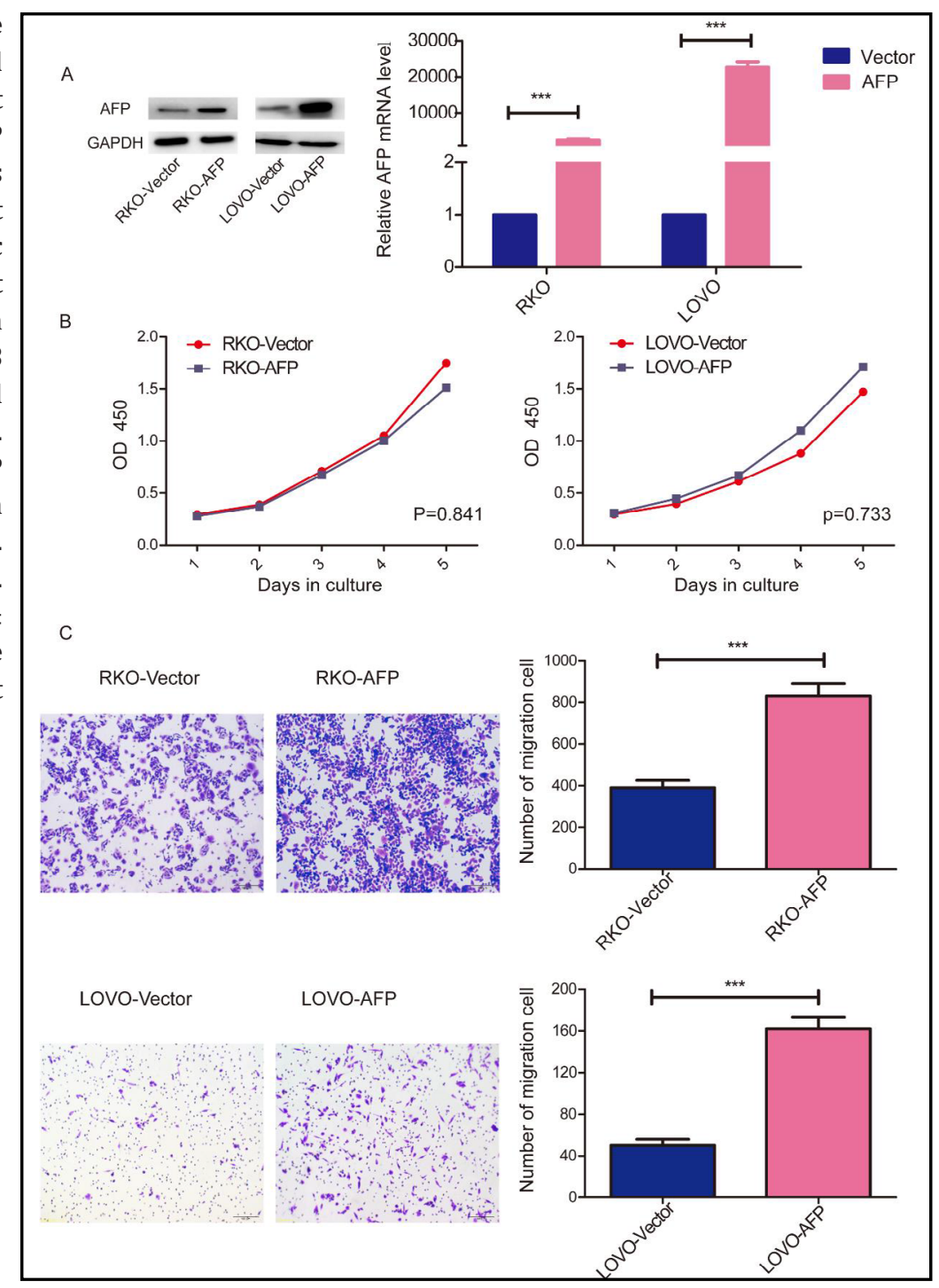

The exact molecular mechanism that could explain the aggressive behavior of AFPproducing tumor remains elusive. Several studies showed that the integrity of hepatocyte growth factor (HGF) and its receptor (c-Met) could regulate cell proliferation and motility, promoting tumor progression [23-25]. In gastric cancer, Amemiya et al. [26] found that a higher frequency of c-Met expression was observed in AFP-producing gastric cancers comparing stage-matched gastric cancers that did not produce AFP. In colorectal cancer, a case study revealed all 3 cases in the study exhibited activation of the HGF/c-Met signaling pathway and speculated that autocrine HGF/c-Met activation may induce the dedifferentiation of common adenocarcinoma cells into stem cell state and produced AFP or hepatoid differentiation [16]. In our study, we found survival rate of the HGF high group was significantly lower than the HGF low group $(p=0.036)$, while survival rate of the c-Met high and c-Met low group didn't reach statistically significance $(p=0.16)$, which may be caused by small sample size. Besides, we found AFP expression was significantly positively correlated with HGF (correlation coefficient of spearman $=0.601$ ) and c-Met (correlation coefficient of spearman $=0.558$ ) expression, which further verified our hypothesis that the bad behavior of AFPP-CRC may be mediated by HGF/c-Met signaling pathway. Further studies are needed to confirm this hypothesis and therapies targeted to the HGF/c-Met signaling pathway may be potentially effective for the treatment of AFPP-CRC.

\section{KARGER}


The incidence of liver metastasis in AFP-positive group was significantly higher than that for negative group ( $\mathrm{P}<0.001) .30 .8 \%$ of AFPP-CRC patients were diagnosed with liver metastasis preoperatively comparing with $7.6 \%$ in the AFP-negative group. In gastric cancer, patients with liver metastasis were found to be presented with a higher serum AFP level [21]. Besides, our study demonstrated the presence of liver metastasis was the only independent prognostic factor for OS in AFPP-CRC. Furthermore, we compared the baseline characteristics of AFP high and AFP low group, and found AFP high group showed significantly more liver metastasis $(p=0.013)$. Therefore, serum AFP level may be a reliable marker to pick out patients at the high risk of liver metastasis and this subgroup of patients may need more intensive follow up and liver metastasis should be specifically targeted in an effort to improve the prognosis of AFPP-CRC.

There are several limitations in this analysis. First, the data were analyzed retrospectively. Besides, we used AFP level $>10 \mu \mathrm{g} / \mathrm{L}$ as an inclusion criterion, however, it is important to remember that serum AFP levels may not rise in the early stages of AFPP-CRC in which a selection bias may be included. Despite of these limitations, previous publications consisted only case series and our study is the first report involving large sample size. We also introduced PSM to balance pronounced differences in baseline characteristics between two groups, which helped reduce the possible selection bias in observational studies.

\section{Conclusion}

In conclusion, AFP-producing CRC had aggressive behavior and their clinicopathologic features are quite different from the AFP-negative group. AFP-positivity is a significant negative predictor of overall survival in patients with colorectal cancer, which may be mediated by HGF/c-Met signaling pathway, and the presence of liver metastasis is the only independent prognostic factor in AFPP-CRC. A better understanding of the characteristics of AFPP-CRC at the cellular and molecular levels is merited for targeting optimal treatment in this unique subgroup.

\section{Abbreviations}

AFP (Alpha-fetoprotein); AFPP-CRC (Alpha-fetoprotein-producing colorectal cancer); AFPN-CRC (AFP-negative colorectal cancer); AFP-GC (AFP-producing gastric cancer); PSM (propensity score matching); IHC (Immunohistochemistry); IRS (immunoreactivity score); HGF (hepatocyte growth factor); c-Met (met proto-oncogene); TNM (Tumor, nodes, metastasis); LNH (lymph node harvested).

\section{Acknowledgements}

This research was supported by the National Science Foundation of China (No. 81702353) and Shanghai Municipal Natural Science Foundation (17ZR1406400). The funders had no role in the study design, data collection and analysis, decision to publish, or preparation of the manuscript. Y. F. and Q. G. L. planned the study. W.X.D. and S.B.M. calculated statistics and analyzed the data. Y. F. and Y. Q. L. wrote the manuscript. S. J. C. and Q. G. L. supervised the entire project. All authors reviewed the manuscript. Informed consent had been obtained and this study was approved by the institutional review board of the Fudan University Shanghai Cancer Center. 


\section{Cellular Physiology Cell Physiol Biochem 2018;51:2052-2064 and Biochemistry \begin{tabular}{l|l} 
DOI: 10.1159/000495824 & (c) 2018 The Author(s). Published by S. Karger AG, Basel \\
www.karger.com/cpb
\end{tabular} \\ Feng et al.: AFP is a Negative Predictor of Overall Survival}

\section{Disclosure Statement}

The authors have no conflicts of interest to disclose.

\section{References}

1 Abelev GI, Perova SD, Khramkova NI, Postnikova ZA, Irlin IS: Production of embryonal alpha-globulin by transplantable mouse hepatomas. Transplantation 1963;1:174-180.

2 Obiekwe BC, Malek N, Kitau MJ, Chard T: Maternal and fetal alphafetoprotein (AFP) levels at term. Relation to sex, weight and gestation of the infant. Acta Obstet Gynecol Scand 1985;64:251-253.

- G Gitlin D, Boesman M: Serum alpha-fetoprotein, albumin, and gamma-G-globulin in the human conceptus. J Clin Invest 1966;45:1826-1838.

4 Adigun 00, Bhimji SS: Alpha Fetoprotein (AFP); in StatPearls. Treasure Island (FL), StatPearls Publishing. StatPearls Publishing LLC., 2017, vol. p.^pp.

5 Norgaard-Pedersen B, Albrechtsen R, Teilum G: Serum alpha-foetoprotein as a marker for endodermal sinus tumour (yolk sac tumour) or a vitelline component of "teratocarcinoma". Acta Pathol Microbiol Scand A $1975 ; 83: 573-589$.

-6 O'Conor GT, Tatarinov YS, Abelev GI, Uriel J: A collaborative study for the evaluation of a serologic test for primary liver cancer. Cancer 1970;25:1091-1098.

7 Huertas Mora RA, Larrodera Lopez L, Gomez Matobella I, Cortes Funes H: [Human B-HCG and AFP as biological markers in germinal testicular tumors]. Rev Esp Oncol 1984;31:321-330.

8 Ishikura H, Fukasawa Y, Ogasawara K, Natori T, Tsukada Y, Aizawa M: An AFP-producing gastric carcinoma with features of hepatic differentiation. A case report. Cancer 1985;56:840-848.

-9 Kuo PC, Chen SC, Shyr YM, Kuo YJ, Lee RC, Wang SE: Hepatoid carcinoma of the pancreas. World J Surg Oncol 2015;13:185.

10 Miyazawa M, Torii T, Toshimitsu Y, Kamizasa N, Suzuki T, Shinozuka N, Ishizawa K, Koyama I: Alphafetoprotein-producing clear cell carcinoma of the extrahepatic bile ducts. J Clin Gastroenterol 2006;40:555557.

11 Liu M, Liu B, Zhou Y, Quan X, Liu B, Dong L: AFP-producing lung squamous carcinoma. Qjm 2016;109:813814.

12 Blandamura S, Vendraminelli R, Aversa S, Fedrigo M: Collecting duct carcinoma of kidney producing alphafetoprotein. Eur J Surg Oncol 2005;31:1039-1041.

13 Randolph LK, Hopkins MK, Hopkins MP, Wasdahl DA: Hepatoid carcinoma of the ovary: A case report and review of the literature. Gynecol Oncol Rep 2015;13:64-67.

$\checkmark 14$ Anzai H, Kazama S, Kiyomatsu T, Nishikawa T, Tanaka T, Tanaka J, Hata K, Kawai K, Yamaguchi H, Nozawa H, Kanazawa T, Ushiku T, Ishihara S, Sunami E, Fukayama M, Watanabe T: Alpha-fetoprotein-producing early rectal carcinoma: a rare case report and review. World J Surg Oncol 2015;13:180.

15 Lin HH, Chang CC, Yang SH, Chang SC, Chen WS, Liang WY, Lin JK, Jiang JK: Elevated serum alphafetoprotein in poorly differentiated adenocarcinoma with neuroendocrine differentiation of the ascending colon: a case report. World J Surg Oncol 2016;14:84.

16 Li J, Liu Y, Xu JH, Xu ZP, Zheng S, Ding KF: Expression of hepatocyte growth factor and c-Met is characteristic of alpha-fetoprotein-producing colorectal adenocarcinoma: A report of three cases. Oncol Lett 2016;11:731-734.

17 Nakajima T, Okazaki N, Morinaga S, Tsumuraya M, Shimosato Y, Saiki S: A case of alpha-fetoproteinproducing rectal carcinoma. Jpn J Clin Oncol 1985;15:679-685.

18 Ooi A, Nakanishi I, Sakamoto N, Tsukada Y, Takahashi Y, Minamoto T, Mai M: Alpha-fetoprotein (AFP)producing gastric carcinoma. Is it hepatoid differentiation? Cancer 1990;65:1741-1747.

19 Reim D, Choi YS, Yoon HM, Park B, Eom BW, Kook MC, Ryu KW, Choi IJ, Joo J, Kim YW: Alpha-fetoprotein is a significant prognostic factor for gastric cancer: Results from a propensity score matching analysis after curative resection. Eur J Surg Oncol 2017;43:1542-1549.

20 Inoue M, Sano T, Kuchiba A, Taniguchi H, Fukagawa T, Katai H: Long-term results of gastrectomy for alphafetoprotein-producing gastric cancer. Br J Surg 2010;97:1056-1061. 


\section{Cellular Physiology Cell Physiol Biochem 2018;51:2052-2064 \begin{tabular}{l|l|l|l} 
DOI: 10.1159/000495824 & (O 2018 The Author(s). Published by S. Karger AG, Basel \\
\hline
\end{tabular} Published online: 6 December 2018 www.karger.com/cpb}

Feng et al.: AFP is a Negative Predictor of Overall Survival

21 Liu X, Cheng Y, Sheng W, Lu H, Xu Y, Long Z, Zhu H, Wang Y: Clinicopathologic features and prognostic factors in alpha-fetoprotein-producing gastric cancers: analysis of 104 cases. J Surg Oncol 2010;102:249255.

-22 Hirajima S, Komatsu S, Ichikawa D, Kubota T, Okamoto K, Shiozaki A, Fujiwara H, Konishi H, Ikoma H, Otsuji E: Liver metastasis is the only independent prognostic factor in AFP-producing gastric cancer. World J Gastroenterol 2013;19:6055-6061.

-23 Matsumoto K, Nakamura T: Hepatocyte growth factor (HGF) as a tissue organizer for organogenesis and regeneration. Biochem Biophys Res Commun 1997;239:639-644.

-24 Halaban R, Rubin JS, Funasaka Y, Cobb M, Boulton T, Faletto D, Rosen E, Chan A, Yoko K, White W, et al.: Met and hepatocyte growth factor/scatter factor signal transduction in normal melanocytes and melanoma cells. Oncogene 1992;7:2195-2206.

25 Tajima H, Matsumoto K, Nakamura T: Regulation of cell growth and motility by hepatocyte growth factor and receptor expression in various cell species. Exp Cell Res 1992;202:423-431.

-26 Amemiya H, Kono K, Mori Y, Takahashi A, Ichihara F, Iizuka H, Sekikawa T, Matsumoto Y: High frequency of c-Met expression in gastric cancers producing alpha- fetoprotein. Oncology 2000;59:145-151. 